\title{
Analysis of Physical and Physiological Parameters of Kabaddi and Kho-Kho Inter-Varsity Players
}

\author{
Vishan Singh Rathore, Arvind Bahadur Singh* \\ Department of Physical Education, Guru Ghasidas University, Bilaspur, Chhattisgarh, India \\ *Corresponding author: arvindsssingh007@ gmail.com
}

Received July 20, 2014; Revised Month August 05, 2014; Accepted August 15, 2014

\begin{abstract}
The main purpose of this study will be to compare selected physical and physiological variables of kabaddi and kho-kho inter-varsity Players. The sample consisted of fifty male kabaddi and kho-kho central zone inter-varsity Players by simple random sampling method. The selected physical fitness variables are agility, strength and flexibility and physiological variables are systolic and diastolic pressure, hemoglobin ( $\mathrm{Hb} \%)$ and resting pulse rate. The results of t-ratio of it showed significant difference in some physical fitness and physiological parameters of kabaddi and kho-kho intervarsity players. In physiological parameters diastolic pressure showed significant difference between kabaddi and kho-kho players. The diastolic pressure of kho-kho intervarsity players more than kabaddi intervarsity players, which may be due to nature of game and movement which demand more blood volume with greater diastolic pressure but systolic pressure, haemoglobin $(\mathrm{Hb} \%)$ and resting pulse rate expressed insignificant difference between kabaddi and kho-kho intervarsity players. The research finding of some physical fitness parameters indicated significant difference between kabaddi and kho-kho intervarsity players. The agility and explosive strength expressed significant difference. The agility of kabaddi intervarsity players more than kho-kho players, which due to quick and speedy movement in catching and raid. The explosive strength of kho-kho players higher than kabaddi intervarsity players but Flexibility showed insignificant difference between kabaddi and khokho players.
\end{abstract}

\section{Keywords: physical fitness, flexibility and Kho-Kho}

Cite This Article: Vishan Singh Rathore, and Arvind Bahadur Singh, "Analysis of Physical and Physiological Parameters of Kabaddi and Kho-Kho Inter-Varsity Players." American Journal of Sports Science and Medicine, vol. 2, no. 5A (2014): 13-16. doi: 10.12691/ajssm-2-5A-4.

\section{Introduction}

Games and sports have been part of human life almost since the time immemorial. Be it a necessity for his survival i.e. hunting for food, shelter and safety from wild animal or other enemies, or as a pursuit of pleasure. The games and sports have been indispensable to mankind, and have become part of the culture. The games and sports are a great unifying force and have tremendous effect on the national and international integration. Through the origin of sports is lost in antiquity, it is quite certain that physical activity has been a part of the life of even primitive men. For him it might have been a basic necessity of life, more than fun and diversion, for his survival depended on it. Hunting, fishing, hurling missiles were activities on which his survival depended. Gradually along with the process of evolution, such activities became more of play and became part of the culture of the tribes. People use sports and games as a mode of transmitting the cultural heritage of their tribes. Games sports and physical activities persisted despite the rise and fall of ancient civilizations and became strongly embedded in the history of civilization as a culture heritage, which was passed on from one generation to another. Today, games and sports have emerged as universal cultural phenomena.

Sports and games propagate the feelings of nationalism and help in creating a new generation of individuals with the feelings that the difference based on caste, community and religion have no meaning and faith in love and peace, in purity, in the feeling of goodwill and brotherhood serves to a greater extent towards humanity. Sports and games provide a common platform where sportsperson for different regions, professing different religions and faiths, speaking different languages, having different customs and traditions interact with each other in a harmonious and congenial atmosphere where they forget all their differences and emerge as a homogenous group. Such type of thinking, insight and mental approach can play positive role in nation integration. Sports and games help in creating such understanding and can play a very decisive and pivotal role in bringing about national integration.

The main purpose of this study will be to compare selected physical and physiological variables of Kabaddi and Kho-Kho inter-varsity Players.

On the basis of available literature and the researcher's own knowledge, about the problem, it is hypothesized that there will be significant difference in physical and physiological variables of Kabaddi and Kho-Kho intervarsity players. 


\section{Materials and Methods}

\subsection{Subjects}

The sample consisted of fifty male Kabaddi and KhoKho central zone inter-varsity Players of each game and their aged ranged between 18 to 28 years. All subjects had participated in central zone interuniversity Kabbadi tournament, session 2013-14 held at Kakatiya University, Warangal, Andhra Pradesh from 25-11-2013 to 28-112013 and central zone Kho-Kho tournament held at Uttkal University, Bhuneshwar, Orissa from 17-12-2013 to 2012-2013 respectively. The players were informed about the essence of the studies planned, and they as well as their coaches consented to voluntary testing.

The subject selected for this study was fifty male Kabaddi and fifty Kho-Kho central zone inter-varsity players of various university teams for collection of data.

The sample consisted 100 subjects selected by simple random sampling method. The selected physical fitness variables are agility, strength and flexibility and physiological variables are systolic and diastolic pressure, hemoglobin $(\mathrm{Hb} \%)$ and resting Pulse Rate

\subsection{Statistical Analysis}

The statistical analysis of the data gathered for the comparison of physical fitness and physiological parameters of Kabaddi and Kho-Kho inter-varsity players analyzed by using statistical independent ' $t$ ' test. To testing the hypothesis the level of significance at 0.05 level of confidence was considered adequate for the purpose of this study.

\section{Results}

Results were presented in tables, graph and interpreted as follows:

Table 1. Mean, Standard deviations and' $t$ ' value of Agility of Kabaddi and Kho- Kho intervarsity Players

\begin{tabular}{|c|c|c|c|c|c|}
\hline S.No. & Groups & N & Mean & S ,D & 't' Value \\
\hline 1 & Kabaddi Players & 50 & 11.85 & .72 & \multirow{2}{*}{$4.24^{*}$} \\
\hline 2 & Kho-Kho Players & 50 & 11.27 & .61 & \\
\hline
\end{tabular}

*Significant at 0.05 level of confidence, Tabulated ' $t$ ' value 3.18 .

Table 1 showed that the mean and standard deviation of kabaddi and kho-kho intervarsity players of agility were $11.85,11.27$ and $.72, .61$ respectively which showed that there is partial difference in agility of kabaddi and khokho intervarsity players. Both groups' players have approximately similar agility. When these scores were subjected to ' $t$ ' test gives out calculated value 4.24 which was higher than tabulated value at 0.05 level. Therefore it reveals that there is significant difference in agility of kabaddi and kho-kho intervarsity players.

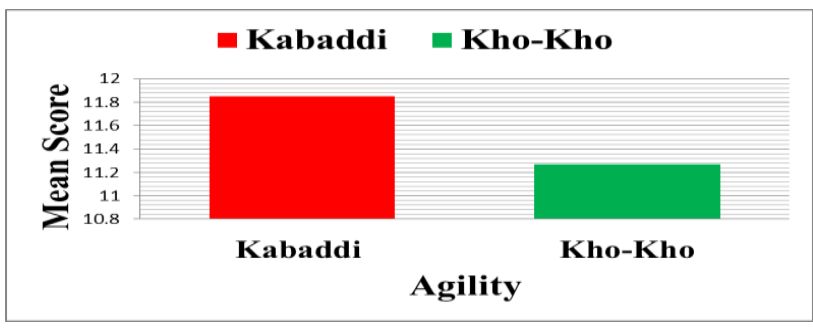

Figure 1. Showing Mean Score of Agility
Table 2. Mean, Standard deviations, and ' $t$ ' value of Explosive Strength of Kabaddi and Kho- Kho intervarsity Players

\begin{tabular}{|c|c|c|c|c|c|}
\hline S.No. & Groups & N & Mean & S ,D & 't' Value \\
\hline 1 & Kabaddi Players & 50 & 33.85 & 4.57 & \multirow{2}{*}{12.85} \\
\cline { 1 - 5 } 2 & Kho-Kho Players & 50 & 46.00 & 4.86 & \\
\hline
\end{tabular}

*Significant at 0.05 level of confidence, Tabulated ' $t$ ' value 3.18.

Table 2 showed that the mean and standard deviation of kabbadi and kho-kho intervarsity players of explosive strength were $33.85,46.00$ and $4.57,4.86$ respectively which showed that there is significant difference in explosive strength of kabaddi and kho-kho intervarsity players. Kho-kho players have more explosive strength than kabaddi. When these scores were subjected to ' $t$ ' test gives out calculated value 12.85 which was higher than tabulated value at 0.05 level. Therefore it reveals that there is highly significant difference in explosive strength of kabaddi and kho-kho intervarsity players.

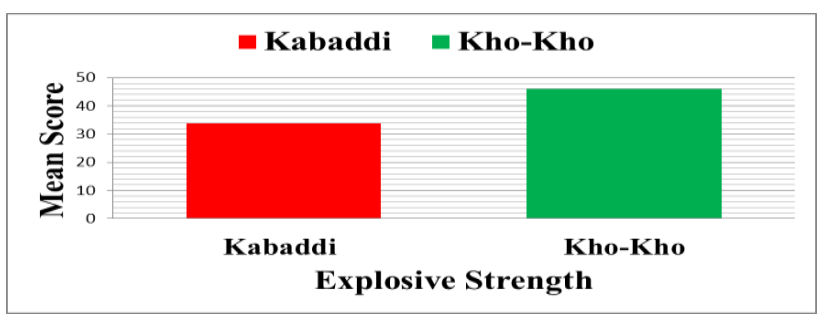

Figure 2. Showing Mean Score of Explosive Strength

Table 3. Mean, Standard deviations and ' $t$ ' value of Flexibility of Kabaddi and Kho- Kho intervarsity Players

\begin{tabular}{|c|c|c|c|c|c|}
\hline S. No. & Groups & $\mathbf{N}$ & Mean & SD & 't' Value \\
\hline 1 & Kabaddi Players & 50 & 37.38 & 4.38 & \multirow{2}{*}{1.52} \\
\cline { 1 - 4 } 2 & Kho-Kho Players & 50 & 36.29 & 2.52 & \\
\hline
\end{tabular}

*Significant at 0.05 level of confidence, Tabulated ' $t$ ' value 3.18.

Table 3 showed that the mean and standard deviation of kabbadi and kho-kho intervarsity players of flexibility were $37.38,36.29$ and $4.38,2.52$ respectively which showed that there is difference in flexibility of kabaddi and kho-kho intervarsity players. When these scores were subjected to ' $t$ ' test gives out calculated value 1.52 which was lower than tabulated value at 0.05 level. Therefore it reveals that there is no significant difference in flexibility of kabaddi and kho-kho intervarsity players.

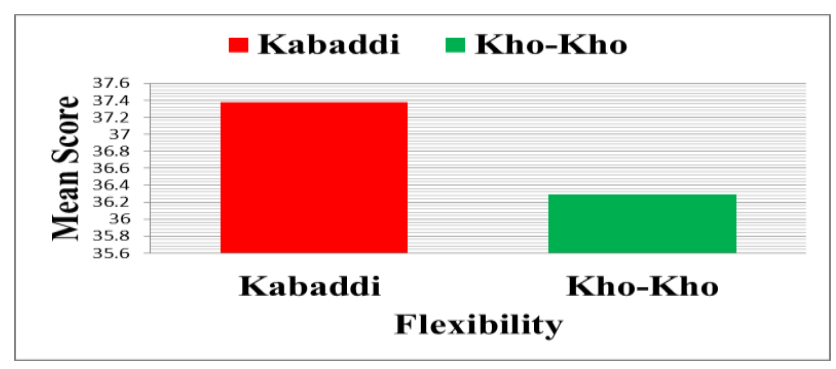

Figure 3. Showing Mean Score of Flexibility

Table 4. Mean, Standard deviations and ' $t$ ' value of Systolic Pressure of Kabaddi and Kho- Kho intervarsity Players

\begin{tabular}{|l|l|l|l|l|l|}
\hline S. No. & Groups & N & Mean & S. D. & 't' Value \\
\cline { 1 - 5 } 1 & Kabaddi Players & 50 & 102.76 & 10.31 & \multirow{2}{*}{.235} \\
\cline { 1 - 4 } 2 & Kho-Kho Players & 50 & 103.22 & 9.20 & \\
\hline
\end{tabular}

*Significant at 0.05 level of confidence, Tabulated ' $t$ ' value 3.18.

Table 4 showed that the mean and standard deviation of kabbadi and kho-kho intervarsity players of systolic 
pressure were $102.76,103.22$ and $10.31,9.20$ respectively which showed that there is partial difference in systolic pressure of kabaddi and kho-kho intervarsity players. The mean of both groups' players have approximately similar systolic pressure. When these scores were subjected to ' $t$ ' test gives out calculated value .235 which was lower than tabulated value at 0.05 level. Therefore it reveals that there is no significant difference in systolic pressure of kabaddi and kho-kho intervarsity play.

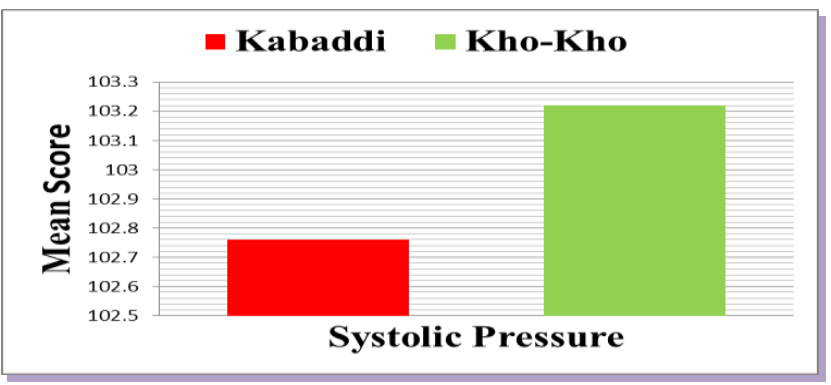

Figure 4. Showing Mean Score of Systolic Pressure

Table 5. Mean, Standard deviations and ' $t$ ' value of Diastolic Pressure of Kabaddi and Kho- Kho intervarsity Players

\begin{tabular}{|c|c|c|c|c|c|}
\hline S. No. & Groups & N & Mean & S. D. & 't' Value \\
\hline 1 & Kabaddi Players & 50 & 63.72 & 10.14 & \multirow{2}{*}{.354} \\
\cline { 1 - 5 } 2 & Kho-Kho Players & 50 & 64.40 & 9.03 & \\
\hline
\end{tabular}

*Significant at 0.05 level of confidence, Tabulated 't' value 3.18.

It is evident from Table 5 that the mean and standard deviation of kabbadi and kho-kho intervarsity players of diastolic pressure were $63.72,64.40$ and 10.14, 9.03 respectively which showed that there is partial difference in diastolic pressure of kabaddi and kho-kho intervarsity players. Both groups' players have approximately dissimilar diastolic pressure. When these scores were subjected to ' $t$ ' test gives out calculated value .354 which was higher than tabulated value at 0.05 level. This implies that there is significant difference in diastolic pressure of kabaddi and kho-kho intervarsity players.

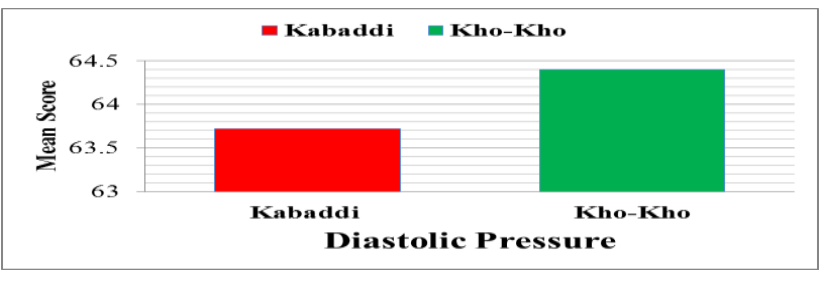

Figure 5. Showing Mean Score of Diastolic Pressure

Table 6. Mean, Standard deviations and ' $t$ ' value of Hemoglobin Percentage of Kabaddi and Kho- Kho intervarsity Players

\begin{tabular}{|c|c|c|c|c|c|}
\hline S.No. & Groups & N & Mean & S D & 't' Value \\
\hline 1 & Kabaddi Players & 50 & 12.98 & 1.13 & \multirow{2}{*}{.990} \\
\hline 2 & Kho-Kho Players & 50 & 13.24 & 1.14 & \\
\hline
\end{tabular}

*Significant at 0.05 level of confidence, Tabulated ' $t$ ' value 3.18 .

Table 6 showed that the mean and standard deviation of kabbadi and kho-kho intervarsity players of hemoglobin percentage were $12.98,13.24$ and $1.13,1.14$ respectively which showed that there is partial difference in hemoglobin percentage of kabaddi and kho-kho intervarsity players. This reveals kho-kho groups' players have higher hemoglobin percentage. When these scores were subjected to ' $t$ ' test gives out calculated value .990 which was lower than tabulated value at 0.05 level. Therefore it reveals that there is no significant difference in hemoglobin percentage of kabaddi and kho-kho intervarsity players.

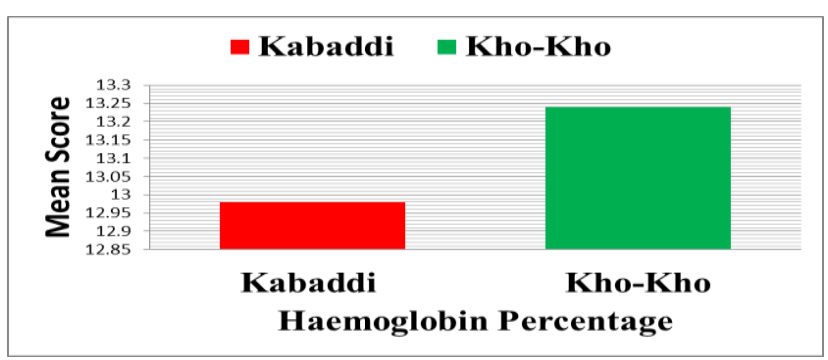

Figure 6. Showing Mean Score of Haemoglobin Percentage

Table 7. Mean, Standard deviations and ' $t$ ' value of Resting Pulse Rate of Kabaddi and Kho- Kho intervarsity Players

\begin{tabular}{|c|c|c|c|c|c|}
\hline S. No. & Groups & N & Mean & S .D & 't' Value \\
\hline 1 & Kabaddi Players & 50 & 68.54 & 4.04 & \multirow{2}{*}{2.28} \\
\hline 2 & Kho-Kho Players & 50 & 66.60 & 4.43 & \\
\hline
\end{tabular}

*Significant at 0.05 level of confidence, tabulated ' $t$ ' value 3.18 .

Table 7 showed that the mean and standard deviation of kabbadi and kho-kho intervarsity players in resting pulse rate were $68.54,66.60$ and 4.04, 4.43 respectively which showed that there is difference in resting pulse rate of kabaddi and kho-kho intervarsity players. The mean of resting pulse rate for kabaddi players higher than kho-kho players. When these scores were subjected to ' $t$ ' test gives out calculated value 2.28 which was lower than tabulated value at 0.05 level. Therefore it reveals that there is no significant difference in resting pulse rate of kabaddi and kho-kho intervarsity players.

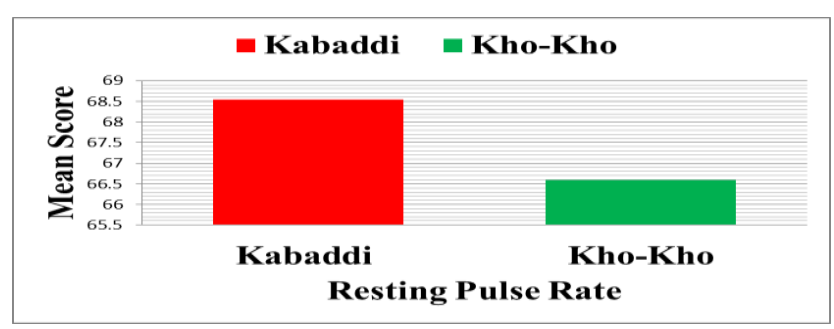

Figure 7. Showing Mean Score of Resting Pulse Rate

\section{Discussion}

The results of t-ratio of it showed significant difference in some physical fitness and physiological parameters of kabaddi and kho-kho intervarsity players. In physiological parameters diastolic pressure showed significant difference between kabaddi and kho-kho players. The diastolic pressure of kho-kho intervarsity players more than kabaddi intervarsity players, which may be due to nature of game and movement which demand more blood volume with greater diastolic pressure but systolic pressure, haemoglobin $(\mathrm{Hb} \%)$ and resting pulse rate expressed insignificant difference between kabaddi and kho-kho intervarsity players.

The research finding of some physical fitness parameters indicated significant difference between kabaddi and kho-kho intervarsity players. The agility and explosive strength expressed significant difference. The agility of kabaddi intervarsity players more than kho-kho players, which due to quick and speedy movement in catching and raid. The explosive strength of kho-kho 
players higher than kabaddi intervarsity players but Flexibility showed insignificant difference between kabaddi and kho-kho players.

On the basis of result, it is hypothesized that there were significant difference in agility, explosive strength and diastolic pressure variables of Kabaddi and Kho-Kho inter-varsity players.

It is also hypothesized that there were insignificant difference in others physical and physiological variables of Kabaddi and Kho-Kho intervarsity players.

\section{Conclusion}

On the basis of finding and within the limitation of present study the following conclusion has been drawn. From table-1it was seen that there is no significant difference in systolic pressure of kabaddi and kho-kho intervarsity players. From Table 2 it was seen that there is significant difference in diastolic pressure of kabaddi and kho-kho intervarsity players. From Table 3, it was found seen that there is no significant difference in hemoglobin percentage of kabaddi and kho-kho intervarsity players. From Table 4 it was revealed that there is no significant difference in resting pulse rate of kabaddi and kho-kho intervarsity players. From Table 5 and Table 6 it was seen that there is significant difference in agility and explosive strength of kabaddi and kho-kho intervarsity players. From Table 7 it was seen that there is no significant difference in flexibility of kabaddi and kho-kho intervarsity players.

The following Recommendations are made on the basis of the results from the study which may be useful for the future research work. The study may be repeated to other physiological and Physical fitness variables on the same subjects. The similar study may be repeated on the female subjects. The same study may be repeated on the other class of the society for different age groups. In this study nine variables was taken, but this can be done on more or less variables. The similar study can be carried out on the total Physical fitness. The study can be carried on the basis of different regions. The study may be conducted on the basis of different types of profession.

\section{References}

[1] Ajmer Singh, et.al., Essentials of Physical Education, (New Delhi: Kalyani Publishers, 2005), p. 38

[2] Ajmer Singh, et.al., Essentials of Physical Education, (New Delhi: Kalyani Publishers, 2005), p. 42

[3] Anand, Shyam, UGC, NET/JRF/SLET, Physical Education, Agra: Upkar Prakashan, 2006.

[4] Best, John W. and James V. Khan, Research in Education, New Delhi: Prentice-Hall in India Pvt. Ltd., Tenth Edition, 2008.

[5] Choudhary, Sneha, "Comparison of Selected Physiological Variables of Kho-Kho and Kabaddi Girls Team of Tripura State", Unpublished Master Thesis, Jiwaji University Gwalior, 1980.

[6] Corbin, Charles B. and Ruth Lindsey, Fitness for Life, California: Human Kinetics Publishers, Inc., Fourth Edition, 2002

[7] Dey, Swapan K., et.al., "Anthropometric, Motor Ability and Physiological Profiles of Indian National Club Footballers: A Comparative Study", South African Journal for Research in Sport, Physical Education and Recreation, Vol. 32, No. 1, 2010.

[8] Eckert, Helen M., Practical Measurement of Physical Performance, London: Henry Kimpton Publishers, 1974.

[9] Getchell, Bud, Physical Fitness: A Way of Life, New York: John Wiley \& Sons, Inc. Publication, Second Edition, 1979.

[10] Ghai, C. L., A Textbook of Practical Physiology, New Delhi: Jaypee Brothers Medical Publishers (P) Ltd., Fourth Edition, 1990. 